\title{
BMJ Open Quantifying the utility of taking pills for preventing adverse health outcomes: a cross-sectional survey
}

\author{
Robert Hutchins, ${ }^{1}$ Michael P Pignone, ${ }^{2}$ Stacey L Sheridan, ${ }^{1,2}$ Anthony J Viera ${ }^{1,3}$
}

To cite: Hutchins R, Pignone MP, Sheridan SL, et al. Quantifying the utility of taking pills for preventing adverse health outcomes: a cross-sectional survey. BMJ Open 2015;5:e006505. doi:10.1136/bmjopen-2014006505

- Prepublication history and additional material is available. To view please visit the journal (http://dx.doi.org/ 10.1136/bmjopen-2014006505).

Received 1 September 2014 Revised 19 April 2015 Accepted 21 April 2015

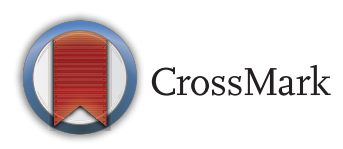

${ }^{1}$ Health Care and Prevention MD-MPH Program, University of North Carolina at Chapel Hill School of Medicine and Gillings School of Global Public Health, Chapel Hill, North Carolina, USA

${ }^{2}$ Department of Medicine, Division of General Internal Medicine and Clinical Epidemiology, University of North Carolina at Chapel Hill, Chapel Hill, North Carolina, USA

${ }^{3}$ Department of Family Medicine, University of North Carolina at Chapel Hill, Chapel Hill, North Carolina, USA

Correspondence to Dr Anthony J Viera; anthony_viera@med.unc.edu

\section{ABSTRACT}

Objectives: The utility value attributed to taking pills for prevention can have a major effect on the costeffectiveness of interventions, but few published studies have systematically quantified this value. We sought to quantify the utility value of taking pills used for prevention of cardiovascular disease (CVD).

Design: Cross-sectional survey.

Setting: Central North Carolina.

Participants: 708 healthcare employees aged 18 years and older.

Primary and secondary outcomes: Utility values for taking 1 pill/day, assessed using time trade-off, modified standard gamble and willingness-to-pay methods.

Results: Mean age of respondents was 43 years (19-74). The majority of the respondents were female $(83 \%)$ and Caucasian $(80 \%)$. Most $(80 \%)$ took at least 2 pills/day. Mean utility values for taking 1 pill/day using the time trade-off method were: $0.9972(95 \% \mathrm{Cl}$ 0.9962 to 0.9980$)$. Values derived from the standard gamble and willingness-to-pay methods were 0.9967 (0.9954 to 0.9979$)$ and $0.9989(95 \% \mathrm{Cl} 0.9986$ to 0.9991 ), respectively. Utility values varied little across characteristics such as age, sex, race, education level or number of pills taken per day.

Conclusions: The utility value of taking pills daily in order to prevent an adverse CVD health outcome is approximately 0.997 .

\section{BACKGROUND}

The desire to take medicine is perhaps the greatest feature which distinguishes man from animals._-Sir William Osler

Many adults will face the decision about whether to take some type of pill for preventive reasons at some point in their lives. When people take pills, they go through a process that involves, but is not limited to, obtaining the pills, remembering to take the pills, and ingesting the pills. These processes, part of the routine of 'taking pills', can theoretically affect quality of life, even apart from any

Strengths and limitations of this study
- One of largest studies to quantify the utility of
pill-taking.
- Large sample permitted analysis of multiple
subgroups.
- Use of three different utility assessments.
- Respondents were predominantly women.
- Our sample was not representative of the general
population.

adverse effects of the medication itself. If the pills require a prescription or therapeutic monitoring, the process also includes visits to clinicians and pharmacists, which may further affect quality of life.

In assessing the potential value of preventive services, cost-effectiveness analyses attempt to consider all the potential beneficial and detrimental effects of the service, including factors such as the effects of taking a preventive medication daily on quality of life. In such studies, these effects are often measured by assigning a numerical value that represents the relative quality of life effect that a certain state of health carries versus an ideal state of perfect health. This numerical value is termed a 'utility.' Utilities usually range from 0 to 1 , with 0 representing death and 1 representing perfect health. Using an accurate utility value for the effect of taking a preventive medication is important, as relatively small changes in the utility can have large effects on the costeffectiveness of the preventive service. ${ }^{1-3}$

Many studies have addressed the effect of quantity and complexity of prescribed medication regimens on adherence, and many others have attempted to quantify patient utilities for certain health conditions. ${ }^{4-6}$ However, based on our extensive literature review (in July 2013), prior to conducting this study, we were aware of only two studies that included a systematic effort to quantify the utility value of taking pills. ${ }^{7} 8$ In these two 
studies, 57 and 70 patients were interviewed using the time trade-off (TTO) utility assessment method. The investigators found a utility value of 0.998 for taking daily aspirin in both studies, and 0.987 for taking warfarin (including monitoring) in one study, and 0.988 for taking warfarin in the second study. Additional studies cite a utility value or discount value to taking pills, ${ }^{1-3} \quad 6 \quad 9-21$ although some of these studies seem to have chosen values arbitrarily, based on expert opinion, or based on other published articles. A recent study estimated people's threshold for daily pill-taking by interviewing 360 people in London, asking the amount of life they would need to gain to take a daily pill for the rest of their life. They found that the median amount of gain 'required' was 6 months, with an IQR of 1-36 months. ${ }^{22}$

Given the limitations of previous studies, we sought to better assess people's utilities for pill-taking. In this paper, we report the results of the first of two large crosssectional studies we conducted to quantify the utility of taking pills for the purpose of trying to prevent a heart attack or stroke, using three different methods: TTO, standard gamble (SG) and willingness to pay (WTP). ${ }^{23}$ Second, we sought to understand whether the average utility value varies by demographics and other characteristics. This information would be useful for researchers conducting cost-effectiveness analyses of preventive interventions that involve pill-taking, as well as to policymakers who help determine which interventions will be accepted for reimbursements by publicly funded programmes.

\section{METHODS}

\section{Survey development}

This cross-sectional study, conducted in April 2013, used a survey to assess people's utilities and was granted exemption status by the Institutional Review Board of the University of North Carolina.

To pretest and refine the utility assessment methods, we used a single focus group of eight people. After gaining informed consent, we tested participants' understanding of each of four utility measurement methods: rating scale, TTO, WTP and SG. We chose these four measurement strategies based on their use in prior studies because each has distinct advantages and disadvantages. ${ }^{24}$

Similar to previous studies, we found that when we asked test questions using the rating scale method (eg, a scale of $0-100$ ), participants overestimated the disutility of taking pills, often assigning utility values of 0.7 or lower to taking 1 pill/day-a value which would be comparable to non-disabling stroke $(0.75) .{ }^{7}$ Additionally, the rating scale method precludes use of a trade-off when measuring the disutility. Therefore, we did not retain this method. Based on pretesting and on past studies, the TTO seemed to have the best understandability and face validity; we also retained the SG and WTP to help provide convergent validity.

Our survey (see online supplementary appendix 1), which we administered using an online survey site, consisted of a total of 19 items. Following a consent page, initial items asked about the respondent's personal pill regimen as well as about how specific qualities of pills (eg, size, shape) affect the difficulty of taking a pill. Subsequent sections elicited utilities via various methods. Questions included a series of TTO method questions, and one question each to assess utility via WTP method and a modified SG method. For these assessments, we asked participants to assume the pills had no side effects and no costs, thus, we were explicitly testing the isolated utility of taking pills because side effects and costs should be dealt with separately in a cost-effectiveness or cost-utility analysis. We included questions to ascertain the numeracy level ${ }^{25} 26$ of each respondent, followed by a final section asking for basic demographic information.

We pilot tested the survey using a convenience sample of seven people to gather further feedback on ease of completion and clarity of questions. Based on feedback, we refined a few items to maximise clarity.

\section{Participant selection}

We recruited participants in two ways. First, an informational email advertising the study and asking for volunteers was sent to all UNC Healthcare employees. Second, an informational newsletter advertisement was placed in the UNC Healthcare employee and UNC School of Medicine newsletters. The email advertisement had a potential reach of 8592, and the newsletter advertisements had a potential reach of approximately 10000 , but many people receive these in duplicate. The only criterion for eligibility was age 18 years or older. By completing the survey, participants were given the opportunity to enter a draw for a US $\$ 200$ VISA gift card.

\section{Variables}

Our main outcomes were utility values for taking 1 pill/ day, using a TTO utility assessment method. We also obtained a utility value for taking 1 pill/day using a modified SG and a modified WTP method, and examined the utility of taking two pills daily or one pill two times a day using TTO as well. Participants rated difficulty obtaining medications and difficulty paying for medications on a scale from 1 to 5 . For analysis, these difficulty levels were then combined into three categories: not difficult, neutral and difficult. Additionally, numeracy was assessed using a previously validated threequestion numeracy questionnaire, with overall numeracy level, then categorised as either 'low' if the respondent got $0-1$ correct answers or 'adequate' if the respondent got 2-3 answers correct. ${ }^{25} 26$

\section{Data analysis}

The TTO utility value was derived by dividing the amount of time each respondent was willing to give up by the approximate amount of time each respondent had remaining in his or her life (using an average life expectancy of 78 years) and subtracting from 1 
(see online supplementary appendix 2). Although other studies carry out a TTO assessment by varying the amount of time the respondent is willing to trade until a point of indifference between the two states is reached, ${ }^{527}$ we modified this method to allow us to include a single item in the survey. Some survey respondents did not enter age in the survey, which prevented us from being able to calculate a TTO utility value. Participants with missing age data $(n=95)$ were excluded from the TTO analysis.

The utility value for SG was calculated as 1 minus the risk of death the participant was willing to accept for the alternate treatment that did not require pill-taking (see online supplementary appendix 2). Again, in order to accommodate evaluating utility within a survey, our assessment was a modified version of other studies' assessments which vary the gamble of death until a point of no preference is reached. ${ }^{27} 29$ The utility value using WTP was derived by dividing the amount a participant was willing to pay (to not have to take a pill) by their total estimated remaining earnings through an average retirement age of 65 years and subtracting from 1 (see online supplementary appendix 2). We used the middle value from whichever income category the participant selected. We excluded all participants who did not provide an age $(\mathrm{n}=95)$ and those who were older than 65 years $(n=19)$. The responses received for WTP varied significantly in range, which led to some utility values being considerable outliers. Therefore, we also excluded WTP-based utility values below $0.95 \quad(n=4)$. Two of those values were the result of extreme outliers with corresponding WTP values of US\$1000 000000 and US\$1000 000. A total of 118 responses were excluded from the WTP analysis.

Participant responses to TTO, SG and WTP questions were converted to utility values using Microsoft Excel (Mac 2011, V.14.1.0. Redmond, Washington, USA), after which an analysis was performed using STATA V.12 (StataCorp 2011, Stata Statistical Software: Release 12. College Station, Texas, USA).

We describe basic participant demographics ratings of pill characteristics and average utility values using proportions with $95 \%$ CIs or means with SDs. All utility values were rounded to four decimal places. The utility values are not normally distributed (with median values of 1), but we report means, which is consistent with prior literature ${ }^{4}$ and the notion that there is some disutility, albeit small, from pill-taking. We calculated $95 \%$ CIs using 1000 bootstrapped samples. Kruskal-Wallis tests were used to compare utility values by participant characteristics. A $p$ value $\leq 0.05$ was used to define statistical significance.

\section{RESULTS}

Characteristics of respondents

A total of 758 people opened the survey link, with nine who declined to provide consent. Of the 749 who gave consent and began the survey, 708 finished the survey before it was closed. The rate of completion among all who opened the survey was $708 / 749(\sim 94.5 \%)$. Mean age of respondents was 43 years, with more participants in the over 50 -year-old category $(41 \%)$ than either the $18-35(30 \%)$ or the $36-50(29 \%)$ year old categories (table 1).

Most participants were female $(83 \%)$ and Caucasian $(80 \%)$, and almost all participants had health insurance $(99 \%)$. Additionally, almost half had annual household incomes greater than US\$75000 (48\%) with about 85\% having at least a college degree. Approximately $84 \%$ had adequate numeracy, and $61 \%$ rated their health as very good or excellent. Less than $8 \%$ of participants reported any degree of difficulty obtaining their pills, while about

\begin{tabular}{|c|c|c|}
\hline Characteristic & $\mathbf{n}$ & N (\%) \\
\hline Mean age & 613 & 43 years \\
\hline Age group (years) & 613 & \\
\hline $18-35$ & & $211(29.8)$ \\
\hline $36-50$ & & $206(29.1)$ \\
\hline$>50$ & & $291(41.1)$ \\
\hline Percentage of females & 708 & $590(83.3)$ \\
\hline Race $^{\star}$ & 708 & \\
\hline Caucasian & & $565(79.8)$ \\
\hline African-American & & $80(11.3$ \\
\hline Other & & $63(8.9)$ \\
\hline Income & 708 & \\
\hline$<\$ 25000$ & & $43(6.1)$ \\
\hline$\$ 25000-\$ 75000$ & & $323(45.6$ \\
\hline$>\$ 75000$ & & $342(48.3)$ \\
\hline$<$ College degree & 708 & $104(14.7)$ \\
\hline Numeracy & 708 & \\
\hline 0 correct & & $31(4.4)$ \\
\hline 1 correct & & $84(11.9)$ \\
\hline 2 correct & & $231(32.6)$ \\
\hline 3 correct & & $362(51.3)$ \\
\hline Health* & 708 & \\
\hline Poor & & $4(0.6)$ \\
\hline Fair & & $51(7.2)$ \\
\hline Good & & $223(31.5)$ \\
\hline Very good & & $317(44.8)$ \\
\hline Excellent & & $113(16.0)$ \\
\hline Percentage of insured & 708 & $698(98.6)$ \\
\hline Difficulty obtaining pills $†$ & 708 & \\
\hline Somewhat difficult & & $52(7.3)$ \\
\hline Very difficult & & $3(0.4)$ \\
\hline Difficulty paying for pills $†$ & 708 & \\
\hline Somewhat difficult & & $106(15.0)$ \\
\hline Very difficult & & $8(1.1)$ \\
\hline Number of times pills taken per day $\geq 2$ & 708 & $358(50.6)$ \\
\hline Number of pills taken per day & 708 & \\
\hline 0 & & $26(3.7)$ \\
\hline 1 & & $113(16.0)$ \\
\hline 2 & & $110(15.5)$ \\
\hline $3+$ & & $459(64.8)$ \\
\hline
\end{tabular}

*Self-reported.

†Rated on five-point scale. 
Table 2 Average utility value for each outcome

\begin{tabular}{|c|c|}
\hline Assessment method & Utility value $(95 \% \mathrm{Cl})$ \\
\hline \multicolumn{2}{|l|}{ Time trade-off* } \\
\hline 1 pill/day & 0.9972 (0.9962 to 0.9980$)$ \\
\hline day & 0.9969 (0.9958 to 0.9977$)$ \\
\hline mes a day & 0.9965 (0.9955 to 0.9973$)$ \\
\hline \multicolumn{2}{|l|}{ Standard gamble } \\
\hline 1 pill/day & 0.9967 (0.9954 to 0.9979$)$ \\
\hline \multicolumn{2}{|l|}{ Willingness-to-pay†‡ } \\
\hline 1 pill/day & 0.9989 (0.9986 to 0.9991$)$ \\
\hline \multicolumn{2}{|c|}{$\begin{array}{l}\text { *Participants with missing age data removed prior to calculating } \\
\text { mean and SD ( } 95 \text { responses removed). } \\
\text { †Participants with missing age data }(n=95) \text { and age } \geq 65(n=19) \\
\text { removed prior to calculating mean and SD ( } 114 \text { responses } \\
\text { removed). } \\
\text { †Outliers below } 0.95 \text { were removed from data prior to calculating } \\
\text { mean and SD ( } 4 \text { responses removed). }\end{array}$} \\
\hline
\end{tabular}

$16 \%$ of participants reported some degree of difficulty paying for their pills. Approximately $65 \%$ took at least 3 pills/day, while only $3.7 \%$ took no pills per day.

\section{TTO utility value}

The average amount of time participants were willing to trade instead of having to take 1 pill/day was 5.0 weeks, which translated to a utility of 0.9972 (table 2 ).

Approximately $87 \%$ of respondents indicated that they would not trade any time (ie, utility of 1.0) in exchange for not having to take 1 pill/day (figure 1). Mean utility value was not significantly different by age, sex, race or education level (table 3). Respondents with lower income levels had lower mean utility values.

We also noted differences based on difficulty obtaining pills, difficulty paying for pills, and number of pills taken per day. Although not statistically significant, the small number of respondents who indicated currently taking no daily pills had a lower mean value for utility of taking pills than those who took at least 1 pill/day, a difference that would likely have meaningful effects on cost-effectiveness analyses.

\section{SG utility value}

Using an SG method, $57.5 \%$ of respondents (figure 2) indicated that they would take no chance of immediate death (0 in 1000000$)$, translating to a utility value of 1.0. The overall average utility value derived by SG for taking 1 pill/day was 0.9967 (table 2). Mean utility value by SG varied slightly by age, sex and education level (table 4).

As with the TTO, those who took no daily pills assigned a lower utility value to taking pills than those who took at least 1 pill/day, although the difference was not statistically significant.

\section{WTP utility value}

Using the WTP method, 9.5\% of respondents (figure 2) indicated that they would pay nothing (US\$0), translating to a utility value of 1.0. The mean amount that respondents were willing to pay to not have to take 1 pill/day, excluding those with missing age data and outliers, was US\$1359. Using this WTP value, the overall average utility for taking 1 pill/day was 0.9989 (table 2). Mean utility value by WTP varied slightly by age, race and education level (table 4 ). Those with a lower numeracy level assigned a higher mean utility value by WTP (0.9994 vs $0.9988, \mathrm{p}<0.001)$.

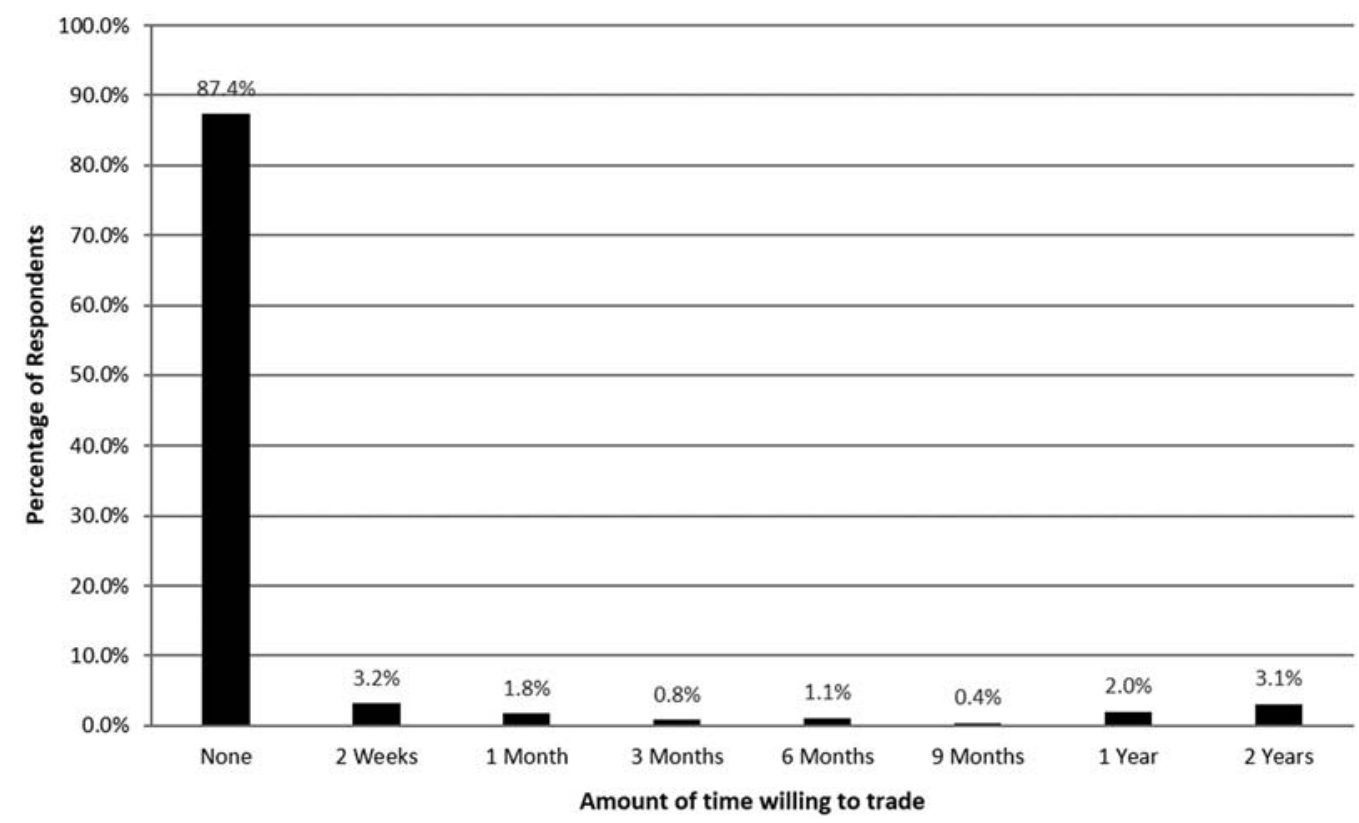

Figure 1 Distribution of Time Trade-Off Responses. As seen in the figure, $87.4 \%$ of respondents were not willing to trade any time in exchange for not having to take a daily pill. Approximately $3 \%$ would trade 2 years. 
Table 3 Mean utility values by participant characteristics*

\begin{tabular}{|c|c|c|c|c|c|c|c|}
\hline \multirow[b]{2}{*}{ Characteristic } & \multirow[b]{2}{*}{$\mathbf{n}$} & \multicolumn{2}{|c|}{1 Pill/day } & \multicolumn{2}{|c|}{2 Pills/day } & \multicolumn{2}{|c|}{1 Pill two times a day } \\
\hline & & Mean & p Valuet & Mean & p Valuet & Mean & p Valuet \\
\hline \multicolumn{8}{|l|}{ Age (years) } \\
\hline $18-35$ & 211 & 0.9987 & \multirow[t]{3}{*}{0.313} & 0.9983 & \multirow[t]{3}{*}{0.416} & 0.9975 & \multirow[t]{3}{*}{0.141} \\
\hline $36-50$ & 206 & 0.9962 & & 0.9957 & & 0.9957 & \\
\hline$>50$ & 196 & 0.9966 & & 0.9965 & & 0.9962 & \\
\hline \multicolumn{8}{|l|}{ Sex } \\
\hline Female & 519 & 0.9974 & \multirow[t]{2}{*}{0.258} & 0.9970 & \multirow[t]{2}{*}{0.903} & 0.9966 & \multirow[t]{2}{*}{0.906} \\
\hline Male & 94 & 0.9959 & & 0.9963 & & 0.9959 & \\
\hline \multicolumn{8}{|l|}{ Race } \\
\hline African-American & 68 & 0.9964 & \multirow[t]{3}{*}{0.142} & 0.9954 & \multirow[t]{3}{*}{0.093} & 0.9949 & \multirow[t]{3}{*}{0.313} \\
\hline Caucasian & 492 & 0.9974 & & 0.9972 & & 0.9969 & \\
\hline Other & 53 & 0.9959 & & 0.9959 & & 0.9949 & \\
\hline \multicolumn{8}{|l|}{ Education level } \\
\hline$<$ College degree & 84 & 0.9974 & \multirow[t]{2}{*}{0.593} & 0.9971 & \multirow[t]{2}{*}{0.416} & 0.9970 & \multirow[t]{2}{*}{0.090} \\
\hline College or graduate degree & 529 & 0.9972 & & 0.9969 & & 0.9964 & \\
\hline \multicolumn{8}{|l|}{ Income } \\
\hline$<\$ 25000$ & 33 & 0.9953 & \multirow[t]{3}{*}{0.005} & 0.9945 & \multirow[t]{3}{*}{0.006} & 0.9943 & 0.012 \\
\hline$\$ 25000-\$ 75000$ & 277 & 0.9972 & & 0.9969 & & 0.9965 & \\
\hline$>\$ 75000$ & 303 & 0.9974 & & 0.9971 & & 0.9968 & \\
\hline Health rating & & & & & & & \\
\hline$<$ Very good & 227 & 0.9967 & 0.810 & 0.9961 & 0.545 & 0.9963 & 0.677 \\
\hline$\geq$ Very good & 386 & 0.9975 & & 0.9973 & & 0.9966 & \\
\hline Numeracy levelł & & & & & & & \\
\hline Low & 93 & 0.9952 & 0.736 & 0.9936 & 0.182 & 0.9941 & 0.875 \\
\hline Adequate & 520 & 0.9975 & & 0.9975 & & 0.9969 & \\
\hline Difficulty obtaining pills & & & & & & & \\
\hline Not difficult & 517 & 0.9976 & 0.008 & 0.9973 & 0.011 & 0.9968 & 0.061 \\
\hline Neutral & 51 & 0.9924 & & 0.9935 & & 0.9939 & \\
\hline Difficult & 45 & 0.9978 & & 0.9957 & & 0.9966 & \\
\hline Difficulty paying for pills & & & & & & & \\
\hline Not difficult & 435 & 0.9978 & 0.014 & 0.9977 & 0.019 & 0.9971 & 0.038 \\
\hline Neutral & 83 & 0.9935 & & 0.9933 & & 0.9933 & \\
\hline Difficult & 95 & 0.9979 & & 0.9965 & & 0.9966 & \\
\hline Number of times pills taken pe & & & & & & & \\
\hline$<2$ & 303 & 0.9963 & 0.003 & 0.9961 & 0.034 & 0.9955 & 0.007 \\
\hline$\geq 2$ & 310 & 0.9980 & & 0.9976 & & 0.9975 & \\
\hline Number of pills taken per day & & & & & & & \\
\hline 0 & 25 & 0.9936 & 0.094 & 0.9944 & 0.233 & 0.9941 & 0.268 \\
\hline 1 & 99 & 0.9969 & & 0.9966 & & 0.9956 & \\
\hline 2 & 96 & 0.9987 & & 0.9980 & & 0.9976 & \\
\hline $3+$ & 393 & 0.9971 & & 0.9968 & & 0.9966 & \\
\hline
\end{tabular}

*Utilities derived using time trade-off technique.

tp Values based on Kruskal-Wallis test.

¥Numeracy level based on number of questions correct on numeracy question (0-1=low; $2-3=$ adequate).

\section{Pill characteristics}

Pill size was the most important characteristic affecting difficulty of pill-taking, with a mean score of 3.06 on a scale of $1-5$ where five represents the greatest influence on difficulty (table 5). Shape was the least important characteristic with a mean score of 2.23.

\section{DISCUSSION}

In a sample of 708 participants, we found the utility of taking a pill daily for CVD prevention to be 0.997 . This value was similar across multiple utility methods, each with its own theoretical strengths and weaknesses, as well as across multiple subgroups, and is consistent with the two previous small studies done using the TTO method. ${ }^{78}$ The value is slightly higher than the range of values of $0.990-0.994$ we found in our subsequent study. ${ }^{23}$ Our subsequent study, however, used a national sample with a higher mean age, a larger proportion of men, and wider range of education levels.

It is important to note that our intent was to specifically measure the hassle of daily pill-taking, separate from the issue of the pill's effectiveness. We accomplished this by asking respondents to consider what they would 


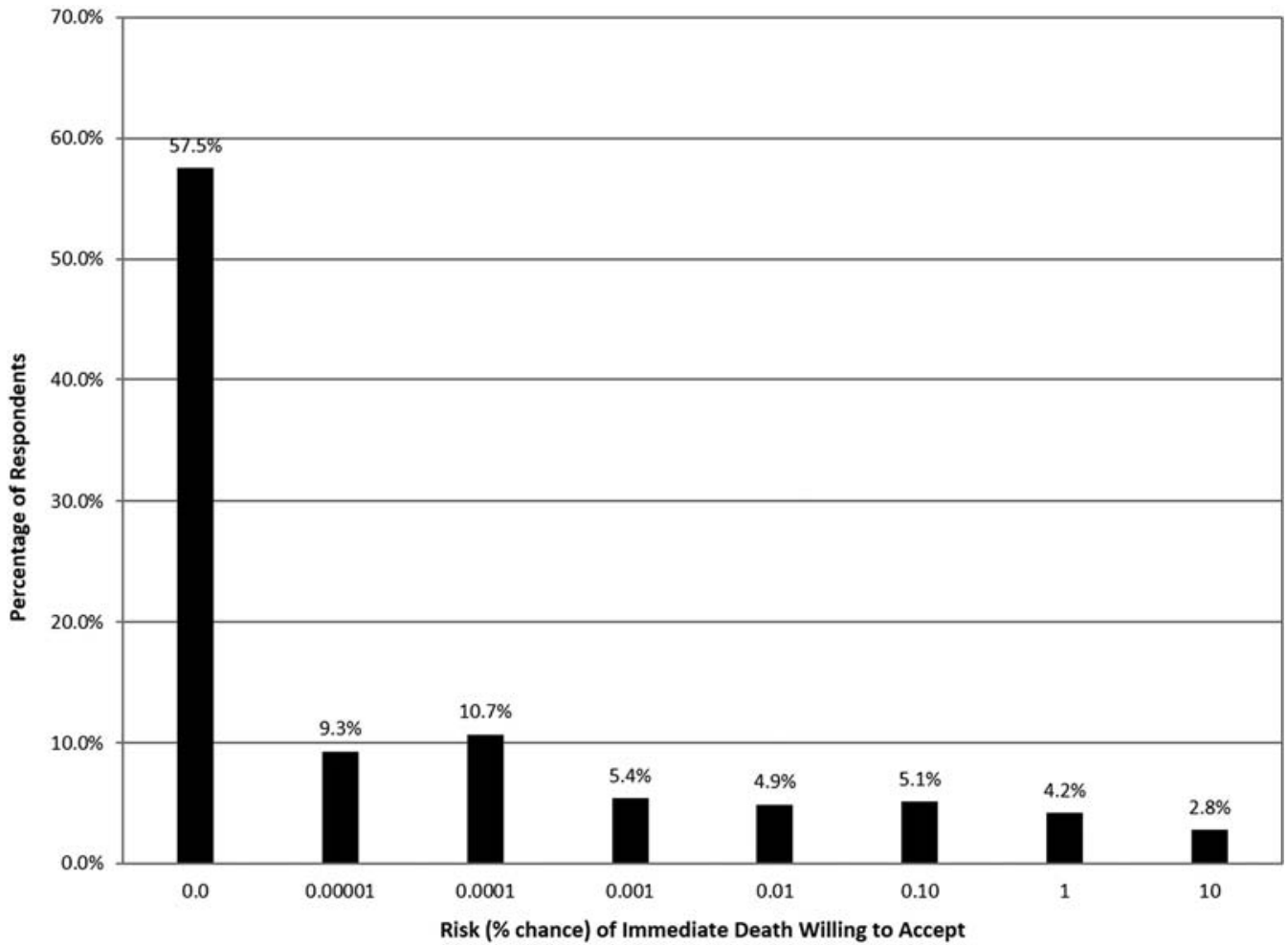

Figure 2 Distribution of Standard Gamble Responses. As seen in the figure, $57.5 \%$ of respondents were not willing to risk any chance of immediate death for not having to take a daily pill. Approximately $3 \%$ accept a $10 \%$ risk.

'trade' for achieving the preventive benefit without requiring daily pill-taking (compared with achieving the benefit but having to take a daily pill). Ideally, respondents thought about all the steps involved in pill-taking, including visits to obtain the prescription, visits to the pharmacy, and actually having to take the pills every day. In other words, we sought to measure the overall health state (utility value) of 'daily pill-taking'.

The utility value of taking a pill daily can have an important effect on cost-effectiveness analyses. Even relatively small decrements in utility like those found in this study can have important effects on quality-adjusted life years (QALYs) for interventions in healthy people where the frequency of outcomes is low. For example, one study examined whether cost-effectiveness of aspirin was sensitive to the assigned utility value of taking the pill. ${ }^{1}$ The base case used a utility value of 1.0 ; the authors then examined the cost per QALY gained across a variety of utility values for taking aspirin. In that analysis, using any utility value below about 0.9996 caused a large increase in the cost per QALY, above the arbitrary but commonly used threshold of US\$50000/QALY for patients at relatively modest baseline cardiovascular disease (CVD) risk. Another study examined the costeffectiveness of the management of chronic non-valvular atrial fibrillation with no treatment, aspirin or warfarin. ${ }^{2}$ Although the authors used a base case utility value of 0.99 for warfarin, they performed a one-way sensitivity analysis varying that utility value from 0.95 to 1.0. The authors found that the results were very sensitive to the assigned utility of taking warfarin. Over that range, the outcome varied from making warfarin the most favoured strategy to the least favoured strategy (compared with aspirin). A third study used a base case utility value of 0.999 for taking a statin daily for 10 years and found a cost/QALY gain of US\$34995 for a 55-year-old man. ${ }^{3}$ Assuming no disutility from taking a pill and altering that utility value to only 1.0 , the cost/QALY decreases nearly $25 \%$ to US\$26 394. Such analyses highlight the importance of having an accurately measured utility value for pill-taking, rather than simply relying on arbitrary levels or expert opinion, as has been done previously.

Our results are comparable to two prior studies that measured a utility value for pill-taking, though our study sample is 10 times larger in number. ${ }^{78}$ Our utility value of 0.997 is similar to the value of 0.998 found in prior studies for taking aspirin, and is higher than the values for taking warfarin noted in prior studies: 0.987 and 0.988 . The lower values for taking warfarin are likely due to those studies including within the utility of taking the pill the additional utility of the INR monitoring and lifestyle limitations such as avoidance of excessive alcohol and contact sports. We sought to examine the utility of the daily pill-taking process itself, viewing aspects such as bothersome side effects, activity limitations, and any required therapeutic monitoring as separate issues, which would vary from pill to pill.

We are aware of at least 17 additional studies that use a utility value of taking pills in their analyses. All these studies cited values between 0.95 and 1.0, depending on 
Table 4 Mean utility value of taking 1 pill/day by participant characteristics*

\begin{tabular}{|c|c|c|c|c|c|c|}
\hline \multirow[b]{2}{*}{ Characteristic } & \multicolumn{3}{|c|}{ Standard gamble } & \multicolumn{3}{|c|}{ Willingness-to-pay†,‡ } \\
\hline & $\mathbf{n}$ & Mean & p Value ${ }^{\star}$ & $\mathrm{n}$ & Mean & p Value ${ }^{\star}$ \\
\hline \multicolumn{7}{|l|}{ Age (years) } \\
\hline $18-35$ & 211 & 0.9966 & \multirow[t]{3}{*}{0.003} & 210 & 0.9989 & \multirow[t]{3}{*}{0.017} \\
\hline $36-50$ & 206 & 0.9973 & & 204 & 0.9992 & \\
\hline$>50$ & 291 & 0.9963 & & 176 & 0.9985 & \\
\hline \multicolumn{7}{|l|}{ Sex } \\
\hline Female & 590 & 0.9966 & \multirow[t]{2}{*}{0.006} & 504 & 0.9989 & \multirow[t]{2}{*}{0.119} \\
\hline Male & 118 & 0.9974 & & 86 & 0.9985 & \\
\hline \multicolumn{7}{|l|}{ Race } \\
\hline African-American & 80 & 0.9934 & \multirow[t]{3}{*}{0.225} & 68 & 0.9992 & \multirow[t]{3}{*}{0.010} \\
\hline Caucasian & 565 & 0.9973 & & 472 & 0.9989 & \\
\hline Other & 63 & 0.9957 & & 50 & 0.9985 & \\
\hline \multicolumn{7}{|l|}{ Education level } \\
\hline$<$ College degree & 104 & 0.9950 & \multirow{2}{*}{0.011} & 80 & 0.9993 & \multirow{2}{*}{0.012} \\
\hline College or graduate degree & 604 & 0.9970 & & 510 & 0.9988 & \\
\hline \multicolumn{7}{|l|}{ Income level } \\
\hline$<\$ 25000$ & 43 & 0.9971 & \multirow{3}{*}{0.713} & 30 & 0.9963 & \multirow{3}{*}{0.164} \\
\hline$\$ 25000-\$ 75000$ & 323 & 0.9966 & & 269 & 0.9989 & \\
\hline$>\$ 75000$ & 342 & 0.9968 & & 291 & 0.9991 & \\
\hline \multicolumn{7}{|l|}{ Health rating } \\
\hline$<$ Very good & 278 & 0.9964 & \multirow{2}{*}{0.167} & 220 & 0.9987 & \multirow{2}{*}{0.314} \\
\hline$\geq$ Very good & 430 & 0.9969 & & 370 & 0.9989 & \\
\hline \multicolumn{7}{|l|}{ Numeracy level§ } \\
\hline Low & 115 & 0.9919 & \multirow[t]{2}{*}{0.059} & 91 & 0.9994 & \multirow[t]{2}{*}{$<0.001$} \\
\hline Adequate & 593 & 0.9976 & & 499 & 0.9988 & \\
\hline \multicolumn{7}{|l|}{ Difficulty obtaining pills } \\
\hline Not difficult & 594 & 0.9971 & 0.316 & 497 & 0.9989 & 0.147 \\
\hline Neutral & 59 & 0.9962 & & 49 & 0.9985 & \\
\hline Difficult & 55 & 0.9925 & & 44 & 0.9990 & \\
\hline Difficulty paying for pills & & & & & & \\
\hline Not difficult & 493 & 0.9976 & 0.682 & 418 & 0.9988 & 0.545 \\
\hline Neutral & 101 & 0.9969 & & 80 & 0.9991 & \\
\hline Difficult & 114 & 0.9925 & & 92 & 0.9990 & \\
\hline Number of times pills taken per & & & & & & \\
\hline$<2$ & 350 & 0.9961 & 0.263 & 297 & 0.9989 & 0.998 \\
\hline$\geq 2$ & 358 & 0.9973 & & 293 & 0.9989 & \\
\hline Number of pills taken per day & & & & & & \\
\hline 0 & 26 & 0.9953 & 0.107 & 25 & 0.9979 & 0.792 \\
\hline 1 & 113 & 0.9965 & & 98 & 0.9990 & \\
\hline 2 & 110 & 0.9989 & & 93 & 0.9987 & \\
\hline $3+$ & 459 & 0.9963 & & 374 & 0.9989 & \\
\hline
\end{tabular}

the type of pill and whether or not side effects and monitoring were considered. ${ }^{1-3}{ }^{8-21}$ Most of the studies used a value close to 1.0 as their base case and then performed a sensitivity analysis to analyse a range. The lower end of the range of most sensitivity analyses was generally lower than the values that we obtained in this study.

For 'difficulty obtaining pills' and 'difficulty paying for pills' (table 3), the 'neutral' category respondents had a lower mean utility than 'not difficult' and 'difficult'. This counterintuitive finding likely arose from chance.
As expected, as the pill regimen becomes more complex and time-consuming, the utility decreases. From 1 to 2 pills/day to 1 pill two times a day, the utility value incrementally decreased from 0.9972 to 0.9969 to 0.9965 , respectively, using the TTO method. The SG and WTP methods revealed similar values of 0.9967 and 0.9989 , respectively. These findings, along with our results in table 5 , suggest that two things that can be done to minimise the impact of pill-taking on quality of life are keeping pill regimens simple (ie, once daily) and making pills small in size. 
Table 5 Participant rating of importance of characteristics of pills

\section{Characteristic of pill}

\section{Size}

Cost

Taste

Smell

Coating

Shape

${ }^{*}$ Rated on a five-point scale with 1 indicating that the characteristic does not affect the difficulty of taking a pill at all, and 5 indicating that the characteristic greatly affects the difficulty of taking a pill.

\section{Strengths and limitations}

To the best of our knowledge, this study and our subsequent national study ${ }^{23}$ are the largest studies to date to quantify the utility of pill-taking. The large sample allowed us to examine multiple subgroups, an important strength of our study over two previous studies that included fewer than 100 participants each. An additional strength of our study is its use of three different utility assessments.

We found that at least some participants were willing to make trade-offs (ie, had utility values other than 1.0) by each of the methods, including over $90 \%$ of participants with WTP. The low number of people who would not trade any time $(\sim 9 \%)$ is a strength of this method and provides indirect support for using it. We had hypothesised that WTP may be a particularly good method for this type of utility assessment, and our findings suggest promise for its use in other situations requiring the measurement of small decrements in utility. Moreover, our results did not differ greatly between these two methods, providing even further support that our results are sound.

\section{Limitations}

We also acknowledge several limitations. Our respondents were predominantly women, and most had at least a college degree. We noted small differences in mean utility values across some of the characteristics in our sample. Also, our sample was not representative of the general population.

To make our survey feasible and increase the chance of yielding accurate results, we modified the administration of utility assessment methods. Our WTP analysis was modified to adjust for lifetime earnings and did not account for any participants over the typical retirement age of 65 years and also does not account for any income over the age of 65 years. It also assumes that a person's annual income remains stable over a lifetime. Despite these simplifications, our results converged with our other methods.

Because we used 78 years as the mean life expectancy for our calculation of TTO, if a participant expected to live longer than 78 years and responded as such, our final utility value could have been smaller than their 'true' value, indicating more effect on quality of life than in reality. Again, this did not appear to have a major effect on results.

We did not assess test-retest reliability. Utility values may fluctuate over time as individuals adapt to a given health state. Our survey only measured individuals' preferences at one point in time. We note that the differences in results based on previous pill-taking suggest that utility values will change in meaningful ways.

Although we stipulated in our survey instrument that participants would not have to pay for pills and to ignore any potential side effects, we cannot be certain that these issues did not have an effect on participant responses, which could have introduced some error in our utility estimates. We presented items in the survey about problems people may experience when taking daily pills. These items preceded the utility items because we wanted respondents to be cognitively prepared to report their true values. It is possible, though unlikely, that such information may have introduced bias. A future study could randomise the order of survey items. Also, given the added survey response burden it would have created, we chose not to include a method such as the EQ-5D in measuring the disutility of daily pill-taking. Future studies could compare our methods to quality of life scales such as the EQ-5D.

Finally, our utility assessment questions used set intervals in a multiple-choice format rather than allowing respondents to input ('free-text') their answers. However, the options we provided were within a reasonable range of the magnitude of answers we were expecting based on our focus group, pilot testing and literature review. Additionally, 'forced-choice' methods are preferable when using health-related quality of life instruments. ${ }^{24}$

\section{CONCLUSIONS}

The utility value of taking a pill daily to try to prevent an adverse CVD health outcome is approximately 0.997 . Knowing this value is useful for researchers evaluating preventive interventions for CVD that include taking pills, including the decision about taking aspirin or statins, and should be considered in addition to information about the decrements in utility from adverse outcomes such as gastrointestinal bleeding or myopathy. Finally, this study reminds clinicians that patients appreciate once-daily pill regimens and small pills.

Acknowledgements The authors wish to thank Mark A Weaver, PhD, who provided valuable assistance with statistical analyses.

Contributors AJV and MPP conceived of the study. All authors participated in the design of the study. RH and AJV were responsible for acquisition of the data. $\mathrm{RH}$ performed initial analyses. All authors participated in interpretation of the data. RH and AJV drafted the initial manuscript. All authors participated in critical revisions of the manuscript.

Funding This work was supported by the Department of Family Medicine, University of North Carolina School of Medicine. 
Competing interests None declared.

Ethics approval UNC Office of Human Subjects Research.

Provenance and peer review Not commissioned; externally peer reviewed.

Data sharing statement No additional data are available.

Open Access This is an Open Access article distributed in accordance with the Creative Commons Attribution Non Commercial (CC BY-NC 4.0) license, which permits others to distribute, remix, adapt, build upon this work noncommercially, and license their derivative works on different terms, provided the original work is properly cited and the use is non-commercial. See: http:// creativecommons.org/licenses/by-nc/4.0/

\section{REFERENCES}

1. Pignone M, Earnshaw S, Pletcher MJ, et al. Aspirin for the primary prevention of cardiovascular disease in women: a cost-utility analysis. Arch Intern Med 2007;167:290-5.

2. Naglie IG, Detsky AS. Treatment of chronic nonvalvular atrial fibrillation in the elderly: a decision analysis. Med Decis Making 1992;12:239-49.

3. Greving JP, Visseren FLJ, de Wit GA, et al. Statin treatment for primary prevention of vascular disease: whom to treat? Cost-effectiveness analysis. BMJ 2011;342:d1672.

4. Nease RF Jr, Kneeland T, O'Connor GT, et al. Variation in patient utilities for outcomes of the management of chronic stable angina: implications for clinical practice guidelines. JAMA 1995;273:1185-90.

5. Sackett DL, Torrance GW. The utility of different health states as perceived by the general public. J Chronic Dis 1978;31:697-704.

6. Torrance GW. Utility approach to measuring health-related quality of life. J Chronic Dis 1987;40:593-600.

7. Gage BF, Cardinalli AB, Owens DK. The effect of stroke and stroke prophylaxis with aspirin or warfarin on quality of life. Arch Intern Med 1996;156:1829-36.

8. Gage BF, Cardinalli AB, Albers GW, et al. Cost-effectiveness of warfarin and aspirin for prophylaxis of stroke in patients with nonvalvular atrial fibrillation. JAMA 1995;274:1839-45.

9. Augustovski FA, Cantor SB, Thach CT, et al. Aspirin for primary prevention of cardiovascular events. J Gen Intern Med 1998;13:824-35.

10. Coleman $\mathrm{Cl}$, Straznitskas AD, Sobieraj DM, et al. Cost-effectiveness of clopidogrel plus aspirin for stroke prevention in patients with atrial fibrillation in whom warfarin is unsuitable. $A m \mathrm{~J}$ Cardiol 2012;109:1020-5.

11. Eckman MH, Rosand J, Greenberg SM, et al. Cost-effectiveness of using pharmacogenetic information in warfarin dosing for patients with nonvalvular atrial fibrillation. Ann Intern Med 2009;150:73-83.
12. Freeman JV, Zhu RP, Owens DK, et al. Cost-effectiveness of dabigatran compared with warfarin for stroke prevention in atrial fibrillation. Ann Intern Med 2011;154:1-11

13. Lee S, Mullin R, Blazawski J, et al. Cost-effectiveness of apixaban compared with warfarin for stroke prevention in atrial fibrillation. PLOS ONE 2012;7:e47473.

14. Lee S, Anglade MW, Pham D, et al. Cost-effectiveness of rivaroxaban compared to warfarin for stroke prevention in atrial fibrillation. Am J Cardiol 2012;110:845-51.

15. O'Brien CL, Gage BF. Costs and effectiveness of ximelagatran for stroke prophylaxis in chronic atrial fibrillation. JAMA 2005;293:699-706.

16. Pignone M, Earnshaw S, Tice JA, et al. Aspirin, statins, or both drugs for the primary prevention of coronary heart disease events in men: a cost-utility analysis. Ann Intern Med 2006;144:326-36.

17. Pignone M, Earnshaw S, McDade C, et al. Effect of including cancer mortality on the cost-effectiveness of aspirin for primary prevention in men. J Gen Intern Med 2013;28:1483-91.

18. Pink J, Pirmohamed M, Hughes DA. Comparative effectiveness of dabigatran, rivaroxaban, apixaban, and warfarin in the management of patients with nonvalvular atrial fibrillation. Clin Pharmacol Ther 2013;94:269-76.

19. Pletcher MJ, Lazar L, Bibbins-Domingo K, et al. Comparing impact and cost-effectiveness of primary prevention strategies for lipid-lowering. Ann Intern Med 2009;150:243-54.

20. Shah SV, Gage BF. Cost-effectiveness of dabigatran for stroke prophylaxis in atrial fibrillation. Circulation 2011;123:2562-70.

21. Weinstein MC, Stason WB. Economic considerations in the management of mild hypertension. Ann N Y Acad Sci 1978;304:424-36.

22. Fontana M, Asaria $\mathrm{P}$, Moraldo $\mathrm{M}$, et al. Patient-accessible tool for shared decision making in cardiovascular primary prevention: balancing longevity benefits against medication disutility. Circulation 2014;129:2539-46.

23. Hutchins R, Viera AJ, Sheridan SL, et al. Quantifying the utility of taking pills for cardiovascular prevention. Circ Cardiovasc Qua Outcomes 2015;8:155-63.

24. Weinstein M, Torrance G, McGuire A. QALYs: the basics. Value Health 2009;12:55-9.

25. Schwartz LM, Woloshin S, Black WC, et al. The role of numeracy in understanding the benefit of screening mammography. Ann Intern Med 1997;127:966-72.

26. Woloshin S, Schwartz LM, Moncur M, et al. Assessing values for health: numeracy matters. Med Decis Making 2001;21:382-90.

27. Puhan MA, Schünemann $\mathrm{HJ}$, Wong $\mathrm{E}$, et al. The standard gamble showed better construct validity than the time trade-off. J Clin Epidemiol 2007;60:1029-33.

28. van Wijck EE, Bosch JL, Hunink MGM. Time-tradeoff values and standard-gamble utilities assessed during telephone interviews versus face-to-face interviews. Med Decis Making 1998;18:400-5.

29. Ryan M. Eliciting public preferences for healthcare: a systematic review of techniques. Health Technol Assess 2001;5:1-186. 